\title{
Mine or mother's? Exploring the self-ownership effect across cultures
}

\author{
Marius Golubickis $^{1}$ (D) Nerissa S. P. Ho ${ }^{2} \cdot$ Johanna K. Falbén $^{1} \cdot$ \\ Kirsten M. Mackenzie ${ }^{1}$ - Angela Boschetti ${ }^{1} \cdot$ William A. Cunningham $^{3}$. \\ C. Neil Macrae ${ }^{1}$
}

Accepted: 23 June 2018 / Published online: 28 June 2018

(C) The Author(s) 2018

\begin{abstract}
In exploring self-biases in cognition and decision-making, recent research has demonstrated cultural variation in the emergence of the self-ownership effect in memory. Whereas Westerners display enhanced memory for items owned by the self (vs. mother), this effect is reversed among Asian participants. Developing this line of inquiry, here we considered whether cultural influences on ownership extend to other outcomes-specifically, the efficiency of object categorization. In two experiments, Western and Asian participants were required to report if previously assigned items (i.e., pencils and pens) were owned-by-self or owned-by-mother. Results revealed a self-prioritization effect for participants from both cultures, such that responses were faster to self-owned than mother-owned objects. To establish the origin of this effect, the processes underlying task performance were interrogated using a hierarchical drift diffusion model approach. Results of these analyses revealed that the self-ownership effect was underpinned primarily by a pre-decisional bias (i.e., starting point of evidence accumulation). These findings elucidate the extent and origin of the self-ownership effect during object processing.
\end{abstract}

Keywords Self · Ownership · Culture · Decision-making · Drift diffusion model 


\section{Introduction}

As a fundamental psychological construct, the self influences core facets of socialcognitive functioning. It guides thinking and doing, shapes interpersonal exchanges, and provides stability and coherence to the flux of subjective experience (Baars 1988; Boyer et al. 2005; Conway and Pleydell-Pearce 2000; Gallagher 2000; James 1890; Kihlstrom and Klein 1994; Neisser 1988). Little wonder, therefore, researchers have spent decades exploring the effects of self-referential processing on cognition and decision-making. The fruits of these efforts have been considerable, with a powerful message emanating from the literature-selfrelevance exerts a potent influence on stimulus processing and response generation (Baumeister 1998; Conway and Pleydell-Pearce 2000; Heatherton 2011; Sui and Humphreys 2015; Truong and Todd 2017). Quite when and how some of these effects arise, however, remains a matter of continued empirical investigation.

\section{Self-relevance and memory}

Although impacting a range of cognitive outcomes (e.g., Baumeister 1998; Mezulis et al. 2004), research to date has focused mainly on the effects of self-referencing (i.e., associating items with the self) on memory function. A highly reliable finding has emerged from this body of work (Conway 2005; Conway and Pleydell-Pearce 2000; Heatherton et al. 2004). When remembering the past, self-referential encoding affords information a significant benefit in both recognition and recall, a phenomenon termed the self-reference effect (SRE, e.g., Kelley et al. 2002; Macrae et al. 2004; Maki and McCaul 1985; Rogers et al. 1977; Symons and Johnson 1997). In the typical experimental paradigm, following a task in which participants are required to rate the extent to which personality characteristics are descriptive of the self and a familiar other (e.g., best friend, celebrity), items encoded in the context of the self (vs. other) are advantaged in memory (see Symons and Johnson 1997). This benefit has been attributed to the operation of a highly accessible and elaborative self-construct that enriches stimulus encoding and representation, hence facilitates memory performance (Conway and Dewhurst 1995; Johnson et al. 1993; Keenan and Baillet 1980; Klein and Loftus 1988; Rogers et al. 1977; Symons and Johnson 1997).

Reflecting the importance of the self-concept, the effects of self-referencing extend beyond the explicit appraisal (and subsequent recollection) of personality characteristics. In particular, an extensive literature has demonstrated that ownership exerts a powerful influence on judgment and memory (see Dawkins et al. 2017). For example, owned (vs. not owned) objects are treated as psychological extensions of the self (Beggan 1992; James 1890), triggering a host of self-serving judgmental and memorial biases. Typified by the "mere ownership" effect, objects randomly assigned to the self are deemed to be more desirable (Beggan 1992; Belk 1988) and valuable (i.e., endowment effect, Kahneman et al. 1991; Morewedge and Giblin 2015) than equivalent items with no prior self-association, effects that have also been reported in young children (e.g., Fasig 2000; Hay 2006). In addition, 
paralleling the SRE, items owned by the self (vs. another person) are also privileged in memory (i.e., self-ownership effect), even when the basis of ownership is arbitrary and the objects are quite trivial (e.g., Cloutier and Macrae 2008; Cunningham et al. 2008; Turk et al. 2011).

\section{Culture and self-relevance}

Grounded in different patterns of self-construal, cultural factors have been shown to exert significant influence on the products of self-referential processing, including ownership effects (Han and Northoff 2008; Kitayama and Uskul 2011; Markus and Kitayama Markus and Kitayama 1991; Masuda and Nisbett 2006; Sparks et al. 2016). Whereas Western cultures emphasize independence and view the self as distinct from others, Asian cultures value interdependence and see the self as highly interconnected with other people, particularly close family members (Markus and Kitayama 1991; Zhu and Han 2008). An interesting consequence of this interconnectedness is that the benefits of self-referential processing are commonly modified among East Asians (Feng et al. 2013; Zhao et al. 2014; Zhu and Zhang 2002; Zhu et al. 2007). For example, Sparks et al. (2016) recently showed that Asian (vs. Western) participants display a reversed self-ownership effect in memory when objects are associated with a close other; notably, mother (i.e., self $<$ mother) ${ }^{1}$.

Also potentially impacting memory performance are cultural differences in the manner in which objects are perceived (Kitayama and Uskul 2011). Whilst Westerners are believed to process objects in an elemental, piecemeal way; Asians tend to adopt a more holistic strategy, such that they exhibit greater sensitivity to the context in which items are encountered (Masuda and Nisbett 2001, 2006; Nisbett and Masuda 2003). For example, Masuda and Nisbett (2001) showed that, compared to Westerners, East Asians were less likely to recognize target objects if, between study and test, the context in which the objects were encoded was changed. Relatedly, at a perceptual level, Chua et al. (2005) demonstrated that, when viewing complex scenes, whereas Asians fixated faster and longer on background items, Westerners made more saccades to central objects. As a result of these variations in perceptual style (i.e., analytic vs. holistic), it has been suggested that Asians forge weaker connections between objects and the self, hence the benefits of selfreferential processing are attenuated (or abolished). Work of this kind underlines the value of exploring potential cultural differences in self-prioritization during object processing.

That cultural factors shape performance in this way resonates, at least in part, with brain imaging work exploring the neural bases of self-referential and object processing (Han and Humphreys 2016; Han and Northoff 2008; Park and Huang 2010). While this research has revealed that activity in the medial prefrontal cortex (MPFC) differentiates between the self and close others in Westerners (Heatherton

\footnotetext{
1 Although sometimes attenuated in magnitude, the standard memory advantage is typically observed when the self and mother are contrasted among Western participants (Symons and Johnson 1997). In contrast with the current investigation, Sparks et al. (2016) recruited both Asian and Western participants in the West (i.e., Australia).
} 
et al. 2006), among Asians the evidence is somewhat mixed. Although several studies have shown that MPFC does not distinguish the self from mother in Chinese participants (e.g., Wang et al. 2012; Zhu and Zhang 2002; Zhu et al. 2007), other work has revealed a self-bias in both Western and East Asian samples (Chen et al. 2013). In terms of object processing, Gutchess et al. (2006) revealed interesting cultural differences in the regions of the brain that are recruited during the perception of complex scenes. Whereas Westerners (vs. Asians) showed greater activity in object-processing areas in the ventral visual cortex (i.e., areas important for semantic processing), Asians (vs. Westerners) displayed more activation in areas implicated in structural perceptual analyses (i.e., left occipital and fusiform areas).

Pertinent to the current investigation, compared to memorial outcomes (Sparks et al. 2016), perceptual decision-making has been shown to yield a standard selfprioritization effect when the self and mother are contrasted across cultures (Humphreys and Sui 2016; Sui and Humphreys 2015). After coupling arbitrary geometric shapes with person labels (e.g., circle $=$ you, triangle $=$ mother), perceptual-matching judgments (i.e., do the items go together?) are fastest and most accurate for stimulus-pairs associated with the self (vs. mother), an effect that is displayed by Western and Asian participants alike (see Sui et al. 2012, 2014). According to Sui and Humphreys (2015), through reciprocal connections between regions of the prefrontal (i.e., vMPFC) and temporal (i.e., posterior STS) cortices, a Self-Attention Network (SAN) serves to enhance the perceptual salience of personally-relevant material (Kim and Johnson 2012, 2015; Northoff 2016; Schmitz and Johnson 2007; Sui and Gu 2017; Truong and Todd 2017). In turn, this enhanced perceptual salience facilitates stimulus processing and task performance, quite independently of patterns of cultural socialization (Sui et al. 2014).

In pondering these contradictory findings, Sparks et al. (2016) have suggested that inconsistencies in the literature may derive from the specific requirements of the ownership tasks under investigation (e.g., semantic processing vs. perceptual identification) and the manner in which self-referential is operationalized. For example, it is possible that perceptual-matching judgments fail to tap the elaborative processing operations that are acknowledged to drive the effects of stimulusrelevance on recognition and recall (Klein and Loftus 1988; Rogers et al. 1977; Symons and Johnson 1997). In addition, judging geometric shapes that serve as proxies for various social targets (e.g., self, mother, friend, stranger) may be a step removed from the task settings (e.g., personality judgments, object ownership) and stimulus materials (e.g., traits, household items) that are typically employed in work exploring the effects of self-referential processing (e.g., Cunningham et al. 2008; Rogers et al. 1977; Sparks et al. 2016). In the context of ownership and stimulus prioritization, these observations raise an interesting question. What would happen if participants were required to classify meaningful items (cf. geometric shapes) that were either owned-by-self or owned-by-mother in a perceptual decision-making task (Humphreys and Sui 2016; Sui and Humphreys 2015)? Would cultural differences in self-construal trigger divergent effects between Western and Asian participants (Sparks et al. 2016), or would a basic self-prioritization effect emerge regardless of cultural socialization (Sui et al. 2012, 2014)? We explored this issue in the current investigation. 


\section{The current research}

Previously, Golubickis et al. (2018) have demonstrated the benefits of self-relevance (i.e., ownership) on object categorization. In a modified ownership task, participants were initially informed that a class of items (from 2 possible categories) belonged either to the self or another person (i.e., Expt. $1=$ stranger; Expt. 2 = best friend). Afterwards, in an object-classification task, they had to report (as quickly and accurately as possible) whether a series of exemplars from each of the categories was owned-by-self or owned-by-other. The results yielded a basic self-prioritization effect (Humphreys and Sui 2016; Sui and Humphreys 2015), such that ownership facilitated object categorization whether the target of comparison was a stranger or best friend (Sui et al. 2012). Accordingly, here we will adopt this paradigm to investigate the effects of ownership on object categorization in Western and Asian participants, but with an important alteration. On this occasion, the self and mother will be compared (Sparks et al. 2016; Sui et al. 2014).

To explore the processes underpinning task performance, computational modeling (i.e., drift diffusion model (DDM) analysis) will be used to explicate the specific pathway (or pathways) through which ownership influences decisionmaking (e.g., Golubickis et al. 2017, 2018; Macrae et al. 2017). In any task context, there are two distinct ways in which decisional processing can be biased. These pertain to how a stimulus is processed and how a response is generated, with each source of bias reflecting a different underlying component of decisional processing (Voss et al. 2004, 2013; White and Poldrack 2014). Whereas variability in stimulus processing affects the quality of information gathering during decision-making (i.e., dynamic stimulus bias), adjustments in response preparation influence how much evidence is required before a specific judgment is made (i.e., prior or pre-decisional bias). The theoretical value of a DDM analysis resides in its ability to isolate these independent forms of bias, thereby elucidate the component processes that underpin decision-making (Ratcliff 1978; Ratcliff and Rouder 1998; Ratcliff et al. 2016; Voss et al. 2004, 2013; Wagenmakers 2009).

The DDM assumes that, during binary decision-making (e.g., owned-by-self vs. owned-by-other), noisy information is continuously sampled until sufficient evidence is acquired to initiate a response (see Fig. 1 for a schematic representation of the model). The duration of the diffusion process is known as the decision time, and the process itself can be characterized by several important parameters. Drift rate $(v)$ estimates the speed of information gathering (i.e., larger drift rate $=$ faster information uptake), thus is interpreted as a measure of the quality of visual processing during decision-making (White and Poldrack 2014). Boundary separation $(a)$ estimates the distance between the two decision thresholds (i.e., self-owned vs. other-owned), hence indicates how much evidence is required before a response is made (i.e., larger (smaller) values indicate more conservative (liberal) responding). The starting point $(z)$ defines the position between the decision thresholds at which evidence accumulation begins. If $z$ is not centered between the thresholds (i.e., $z=0.5$ ), this denotes an a priori bias in favor of the response that is closer to the starting point (White and Poldrack 2014). In other words, less evidence is 


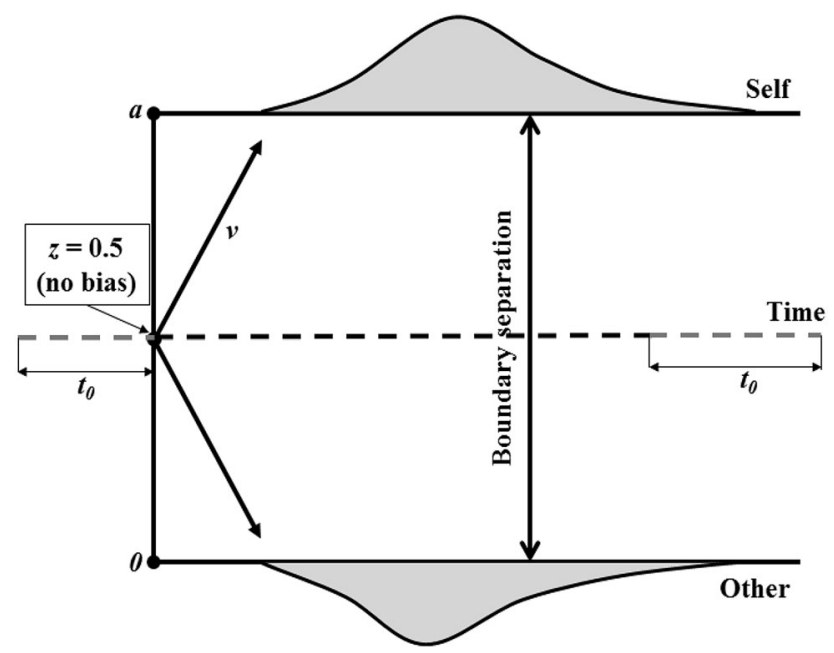

Fig. 1 Schematic representation of the drift diffusion model. An information gathering process begins at starting point $z$ and continues with a mean slope $v$ until it reaches an upper $(a)$ or lower $(0)$ threshold. Non-decision processes $\left(t_{0}\right)$ reflect how much time elapses before/after the decision process. The process durations and outcomes vary from trial to trial because of random noise. Outside the threshold boundaries the response distributions are shown

required to reach the preferred (vs. non-preferred) threshold. Finally, the duration of all non-decisional processes is given by the additional parameter $t_{0}$, which is taken to indicate biases in stimulus encoding and response execution (Voss et al. 2010).

Applied successfully to a wide range of cognitive tasks (see Spaniol et al. 2006; Wagenmakers 2009), a DDM analysis is useful in the current context as it has the capacity to reveal the origin of stimulus prioritization during object categorization. Previously, Golubickis et al. (2018) have shown that, at least among Western participants, differences in the starting point of evidence gathering (i.e., $z$ ) underpin the self-ownership effect. Specifically, displaying an egocentric pre-decisional bias (e.g., Epley and Gilovich 2004; Epley et al. 2004), participants required less evidence when responding to self-owned than either stranger-owned or friendowned items. Albeit with a different target of comparison (i.e., mother), an equivalent effect is expected to emerge in the current work. What remains to be seen, however, is whether a comparable bias underpins responding among Asian participants (Kitayama and Uskul 2011).

\section{Experiment 1}

The goal of Experiment 1 was to explore the effects of self-relevance (i.e., ownership) on object categorization in Western and Southeast Asian participants. Following Golubickis et al. (2018), participants were presented with objects (i.e., pencils or pens) that ostensibly belonged either to the self or mother. Their task was simply to classify the items (i.e., owned-by-self vs. owned-by-mother) as quickly and accurately as possible. Replicating Golubickis et al. (2018), we expected 
Westerners to display a standard self-prioritization effect, such that responses would be faster (and more accurate) to self-owned than mother-owned items. Of empirical interest was whether Southeast Asians would respond in a similar manner (see Sui et al. 2014) or, instead, exhibit an advantage for items owned-by-mother (Sparks et al. 2016). To identify the processes underpinning task performance, data were interrogated using a Hierarchical Drift Diffusion model (HDDM) analysis (Wieki et al. 2013).

\section{Method}

\section{Participants and design}

Forty-eight young adults took part in the study; 24 of whom resided in the West (i.e., Aberdeen, Scotland; 5 males, $M_{\text {age }}=20.21, S D=4.17$ ), and 24 of whom resided in Southeast Asia (i.e., Kuala Lumpur, Malaysia; 14 males, $M_{\text {age }}=26.41$, $S D=4.06){ }^{2}$ All participants had normal or corrected-to-normal visual acuity and reported that, to date, they had lived entirely in either the UK or Malaysia, respectively. Informed consent was obtained from participants prior to the commencement of the experiment and the protocol was reviewed and approved by the Ethics Committee at the School of Psychology, University of Aberdeen. The experiment had a 2 (Culture: Western vs. Asian) $\times 2$ (Ownership: self vs. mother) mixed-design with repeated measures on the second factor.

\section{Stimulus materials and procedure}

Participants were approached individually-in Aberdeen, Scotland and Kuala Lumpur, Malaysia - by an experimenter and asked if they would take part in a brief object-categorization task (Golubickis et al. 2018). On securing their consent, each participant was seated facing a laptop computer and the experimenter explained that the study comprised an object-categorization task featuring two classes of objects; pencils and pens. Next, participants were told that, prior to the commencement of the task, the computer would randomly assign one category of object to them (i.e., owned-by-self) and the other category of object to their mother (i.e., owned-bymother). That is, participants would own all the items (i.e., pencils or pens) from one of the categories, and their mother would own all the items from the other category. Participants then pressed the spacebar on the keyboard and text appeared on the screen revealing who had been assigned the pencils and pens, respectively (e.g., you $=$ pens, mother $=$ pencils). Assignment of the objects to the self and mother was counterbalanced across the Western and Asian samples. The experimenter then explained that, on the computer screen, participants would be presented with a series of pictures of individual pencils and pens and their task was simply to report (via a button press), as quickly and accurately as possible, whether the item belonged to them (i.e., self) or their mother. Using their dominant hand,

\footnotetext{
2 Adopting a Bayesian approach, our sampling plan was to collect data from 24 participants in each location then establish if sufficient evidence had been gathered (Schönbrodt et al. 2017).
} 
participants' responses were given via two buttons on the keyboard (i.e., M \& N). Key-response mappings were counterbalanced across participants and the labels 'mine' and 'mother' were located above the relevant response buttons.

Each trial began with the presentation of a central fixation cross for $1000 \mathrm{~ms}$, followed by the picture of a pencil or pen for $100 \mathrm{~ms}$. After each object was presented, the screen turned blank until participants reported the owner of the item (i.e., self or mother). Following each response, the fixation cross re-appeared and the next trial commenced. The two categories of stimuli comprised photographs of 28 unique objects (14 pencils and 14 pens) that were taken from Google images and edited using Photoshop CS6, such that each pencil or pen was oriented obliquely from the left-bottom to the right-top corner. Images were $140 \times 140$ pixels in size $\left(3.8^{\circ} \times 3.8^{\circ}\right)$, greyscale, and matched for luminance. Participants initially performed 18 practice trials (i.e., 9 pens and 9 pencils randomly drawn from each stimulus set), followed by two blocks of 112 trials in which all stimuli occurred equally often (i.e., 4 times per block) in a random order. In total, there were 224 trials, with 112 trials in each condition (i.e., self-owned trials vs. mother-owned trials). On completion of the task, participants were debriefed, thanked, and dismissed.

\section{Results}

\section{Object categorization}

Responses faster than $200 \mathrm{~ms}$ were excluded from the analysis, eliminating less than $1 \%$ of the overall number of trials. Table 1 shows the accuracy and response time (RT) data. Participants' mean reaction times were submitted to a 2 (Culture: Western vs. Asian) $\times 2$ (Ownership: self vs. mother) Bayesian mixed-model analysis of variance (ANOVA) using the software package JASP, with a default distribution of prior model probabilities (see "Appendix A"-JASP Team 2017; Rouder et al. 2012). Comparison of the resulting models showed that the main effects model (Culture + Ownership, $\mathrm{BF}_{10}=21.44$ ) was preferred to the interaction model (Culture + Ownership + Culture $\times$ Ownership, $\mathrm{BF}_{10}=8.69$ ) by a Bayes Factor of 2.47. Specifically, there was strong evidence for the effect of Ownership $\left(\mathrm{BF}_{10}=13.41\right)$ on task performance, but only anecdotal evidence for the effect of culture $\left(\mathrm{BF}_{10}=1.64\right)$ on object categorization (Wagenmakers et al. 2011). Further analysis of effects revealed limited evidence for the inclusion of Culture

Table 1 Mean reaction time (RT) and accuracy (\%) as a function of culture and ownership (Expt. 1)

\begin{tabular}{llll}
\hline Culture & Ownership & Mean RT (ms) & Accuracy (\%) \\
\hline \multirow{2}{*}{ Western } & Self & $510(47)$ & $93(6)$ \\
& Mother & $531(51)$ & $90(9)$ \\
\multirow{2}{*}{ ssian } & Self & $552(82)$ & $94(6)$ \\
& Mother & $567(82)$ & $90(10)$ \\
\hline
\end{tabular}

Standard deviations appear within parentheses 
$\left(\mathrm{BF}_{\text {Incl }}=1.47\right)$. Thus, regardless of cultural socialization, responses were faster when items were owned-by-self $(M=531 \mathrm{~ms})$ than owned-by-mother $(M=549 \mathrm{~ms})$.

\section{Accuracy}

A 2 (Culture: Western vs. Asian) $\times 2$ (Ownership: self vs. mother) Bayesian mixedmodel ANOVA conducted using JASP, with a default distribution of prior model probabilities, provided only anecdotal evidence for the effect of Ownership on task performance $\left(\mathrm{BF}_{10}=2.05\right.$; see "Appendix $\mathrm{A}$ "), such that accuracy was greater for self-owned $(M=94 \%)$ than mother-owned $(M=90 \%)$ items (Wagenmakers et al. 2011). Further analysis of effects revealed no evidence for the inclusion of Culture $\left(\mathrm{BF}_{\text {Incl }}=0.25\right)$.

\section{Drift diffusion modeling}

Our previous analysis suggested there were no cultural differences in task performance. Given the results reported by Golubickis et al. (2018), we take this to mean that a pre-decisional bias for self-related information does not differ between cultures. To confirm this interpretation, we submitted the current data to a HDDM analysis. HDDM is an open-source software package written in Python for the hierarchical Bayesian estimation of drift diffusion model parameters (Wieki et al. 2013). This approach assumes that the model parameters for individual participants are random samples drawn from group-level distributions and uses Bayesian statistical methods to estimate all parameters at both the group- and individual-participant level (Vandekerckhove et al. 2011). An advantage of this approach is that it is robust at recovering model parameters when less data is available (Wiecki et al. 2013). Models were response coded, such that the upper threshold corresponded to an 'owned-by-self' response and the lower threshold to an 'owned-by-mother' response (Golubickis et al. 2018). As the self-ownership effect was observed across both cultures, only Ownership was modeled in the HDDM analysis.

Based on Dunovan et al. (2014), three models were estimated for comparison (see Table 2). First, a prior bias model (PBM) that allowed starting point ( $z$ ) to vary

Table 2 Deviance Information Criterion (DIC) for each model (Experiments 1 \& 2)

\begin{tabular}{lllll}
\hline Model & Allowed to vary ownership & Fixed & \multicolumn{2}{l}{ DIC } \\
\cline { 3 - 5 } & & & Expt. 1 & Expt. 2 \\
\hline PBM & $z$ & $v$ & -6035 & -6834 \\
DBM & $v$ & $z$ & -5747 & -6431 \\
MSM & $v, z$ & - & -6161 & -6927 \\
\hline
\end{tabular}

$z=$ starting point, $v=$ drift rate. Fixed $z$ indicates a starting value centered between the thresholds $(z=.5)$. A DIC difference of 10 is strong evidence for a model (Kass and Raftery 1995) 
as a function of Ownership (i.e., self vs. mother) was estimated. This model tested whether task performance was underpinned by a prior response bias only (i.e., differences in information sampling requirements). Second, a dynamic bias model (DBM) that allowed drift rate $(v)$ to vary as a function of Ownership (i.e., self vs. mother) was estimated. This model tested whether task performance was underpinned by differences in the efficiency of stimulus processing (i.e., drift rate, v) during decision-making. Finally, a multi-stage model (MSM) was estimated that considered the extent to which task performance was underpinned by a combination of prior (i.e., z) and dynamic (i.e., v) biases.

Bayesian posterior distributions were modeled using a Markov Chain Monte Carlo (MCMC) with 10,000 samples (following 1,000 burn in samples). Outliers (5\% of trials) were removed by the HDDM software (Ratcliff and Tuerlinckx 2002). As can be seen in Table 2, the MSM yielded the best fit (i.e., lowest DIC value). The DIC was adopted as it is routinely used for hierarchical Bayesian model comparison (Spiegelhalter et al. 1998). As diffusion models were fit hierarchically rather than individually for each participant, a single value was calculated for each model that reflected the overall fit to the data at the participant- and group-level. Lower DIC values favor models with the highest likelihood and least number of parameters.

Interrogation of the posterior distributions revealed that task performance was underpinned by a prior bias (see Fig. 2). Specifically, comparison of the observed starting value $(z=.64)$ with no bias (i.e., $z=0.50)$ yielded very strong evidence of a pre-decisional bias toward self-owned responses $\left(p_{\text {Bayes }}(\text { bias }>0.5)<.001\right)^{3}$. A comparison of drift rates $(v$, negative drift rates were first multiplied by -1$)$ yielded no evidence of a difference in the rate of information uptake between self-owned and mother-owned objects (respective $M \mathrm{~s}: 4.20$ vs. $4.02, p_{\text {Bayes }}[$ self $>$ mother] $=.413){ }^{4}$

\section{Discussion}

The results of Experiment 1 furnished evidence that ownership influenced the speed of object categorization regardless of cultural socialization. Compared with pencils or pens that were owned-by-mother, identical self-owned items elicited faster classification times in participants from both the UK and Malaysia. This corroborates the finding that self-relevance facilitates perceptual decision-making among Westerners and Asians alike (Sui et al. 2012, 2014). In exploring the origin of this self-ownership effect, an HDDM analysis yielded evidence for the operation of a prior bias. Replicating Golubickis et al. (2018), ownership mapped onto the

\footnotetext{
${ }^{3}$ Bayesian $p$ values quantify the degree to which the difference in the posterior distribution is consistent with the hypothesis that the parameter is greater for self-owned than mother-owned. For example, a Bayesian $p$ of .05 indicates that $95 \%$ of the posterior distribution supports the hypothesis.

${ }^{4}$ As no substantial evidence for cultural effects was observed in the ANOVA, adding culture to the HDDM models may not be warranted as it is unlikely to moderate any parameters. To ensure completeness however, models were rerun with culture included. As would be expected based on the ANOVA, culture did not modify any parameters and resulted in larger DIC estimates.
} 

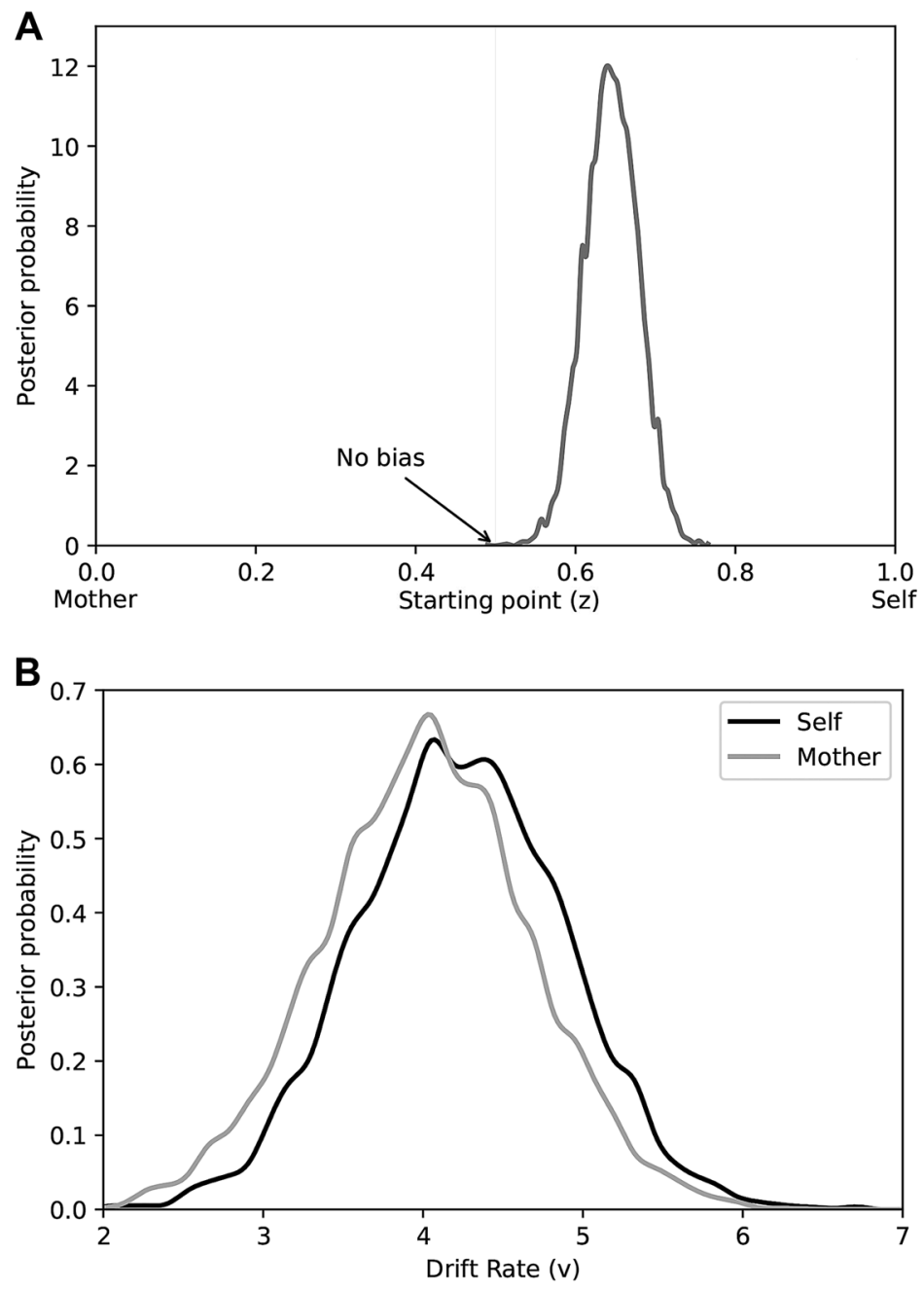

Fig. 2 Mean posterior distributions of starting point $(z)(\mathbf{A})$ and drift rate $(v)$ as a function of Ownership (B). Drift rates for mother have been multiplied by -1

starting value $(z)$ of the DDM, such that participants required less evidence when responding to self-owned than mother-owned items.

Collectively, the current findings provide no evidence that cultural differences between Western and Asian participants reverse (or even attenuate) the selfprioritization effect in object categorization when mother is the target of comparison (cf. Sparks et al. 2016). Instead, objects owned-by-self (vs. object-owned-by mother) were classified more quickly regardless of participants' cultural milieu (Sui et al. 2012, 2014). To establish the replicability of these findings, in our next experiment we explored the self-ownership effect using a different Asian sampleresidents of Hong Kong. Again, in an object-ownership paradigm, participants 
classified items that ostensibly belonged either to the self or mother. As in Experiment 1, data were submitted to an HDDM analysis to elucidate the processes underlying decision-making (Wieki et al. 2013).

\section{Experiment 2}

\section{Method}

\section{Participants and design}

Forty-eight young adults took part in the study; 24 of whom resided in the West (i.e., Aberdeen, Scotland; 7 males, $M_{\text {age }}=21.75, S D=2.98$ ), and 24 of whom resided in East Asia (i.e., Hong Kong, China; 10 males, $M_{\text {age }}=19.92, S D=2.45$ ) ${ }^{5}$ All participants had normal or corrected-to-normal visual acuity and reported that, to date, they had lived entirely in either the UK or Hong Kong, respectively. Informed consent was obtained from participants prior to the commencement of the experiment and the protocol was reviewed and approved by the Ethics Committee at the School of Psychology, University of Aberdeen. The experiment had a 2 (Culture: Western vs. Asian) $\times 2$ (Ownership: self vs. mother) mixed-design with repeated measures on the second factor.

\section{Stimulus materials and procedure}

Participants were approached individually_in Aberdeen, Scotland and Hong Kong, China-by an experimenter and asked if they would take part in a brief objectcategorization task. On securing their consent, each participant was seated facing a laptop computer and the experimenter explained that the study comprised an objectclassification task featuring two classes of objects; pencils and pens. The task was identical to Experiment 1. On completion of the experiment, participants were debriefed, thanked, and dismissed.

\section{Results}

\section{Object categorization}

Responses faster than $200 \mathrm{~ms}$ were excluded from the analysis, eliminating less than $1 \%$ of the overall number of trials. Table 3 shows the accuracy and RT data. Participants' mean reaction times were submitted to a 2 (Culture: Western vs. Asian $) \times 2$ (Ownership: self vs. mother) Bayesian mixed-model analysis of variance (ANOVA) using the software package JASP, with a default distribution of prior model probabilities (see "Appendix B"-JASP Team 2017). Comparison of the resulting models revealed that the main effects model (Culture + Ownership, $\left.\mathrm{BF}_{10}=32.52\right) \quad$ was preferred to the interaction model

\footnotetext{
5 Our sampling plan was as in Experiment 1.
} 
Table 3 Mean reaction time (RT) and accuracy (\%) as a function of culture and ownership (Expt. 2)

\begin{tabular}{llll}
\hline Culture & Ownership & Mean RT $(\mathrm{ms})$ & Accuracy $(\%)$ \\
\hline Western & Self & $512(70)$ & $92(6)$ \\
& Mother & $538(87)$ & $91(6)$ \\
\multirow{2}{*}{ Asian } & Self & $530(68)$ & $95(4)$ \\
& Mother & $546(72)$ & $88(9)$ \\
\hline
\end{tabular}

Standard deviations appear within parentheses

$\left(\right.$ Culture + Ownership + Culture $\times$ Ownership, $\left.\mathrm{BF}_{10}=12.23\right)$ by a Bayes Factor of 2.66. Specifically, there was very strong evidence for the effect of Ownership $\left(\mathrm{BF}_{10}=53.89\right)$ on task performance (Wagenmakers et al. 2011), such that responses were faster to self-owned $(M=521 \mathrm{~ms})$ than mother-owned $(M=542 \mathrm{~ms})$ items. Further analysis of effects revealed no evidence for the inclusion of Culture $\left(\mathrm{BF}_{\text {Incl }}=0.55\right)$.

\section{Accuracy}

A 2 (Culture: Western vs. Asian) $\times 2$ (Ownership: self vs. mother) Bayesian mixedmodel ANOVA conducted using JASP, with a default distribution of prior model probabilities, revealed that the interaction model (Culture + Ownership + Culture $\times$ Ownership, $\mathrm{BF}_{10}=4.14$ ) was preferred to the main effects model (Culture + Ownership, $\mathrm{BF}_{10}=2.79$ ) by a Bayes Factor of 1.48 . Specifically, there was strong evidence for the effect of Ownership $\left(\mathrm{BF}_{10}=11.30\right)$, but no evidence for the effect of Culture $\left(\mathrm{BF}_{10}=0.25\right)$ on performance. Further analysis of effects revealed no evidence for the inclusion of the Ownership $\times$ Culture interaction $\left(\mathrm{BF}_{\text {Incl- }}\right.$ $=1.08)$. Accuracy was higher for self-owned $(M=94 \%)$ then mother-owned $(M=90 \%)$ items.

\section{Diffusion modeling}

As in Experiment 1, no cultural differences in task performance were observed. Again, this suggests that a pre-decisional bias for self-related information does not differ between cultures (Golubickis et al. 2018). To confirm this interpretation, the current data were submitted to a HDDM analysis (Wieki et al. 2013). As the selfownership effect was observed across both cultures, only Ownership was modeled in the HDDM analysis. Three models were tested for comparison. As can be seen in Table 2, the MSM yielded the best fit (i.e., lowest DIC value). Interrogation of the posterior distributions revealed that task performance was underpinned by a combination of prior and dynamic biases (see Fig. 3). Specifically, comparison of the observed starting value $(z=.67)$ with no bias (i.e., $z=0.5)$ yielded very strong evidence of a pre-decisional bias toward self-owned (vs. mother-owned) responses $\left(p_{\text {Bayes }}(\right.$ bias $\left.>0.5)<.001\right)$. In addition, a comparison of drift rates $(v)$ revealed moderate evidence for a difference in the rate of information uptake (negative drift 

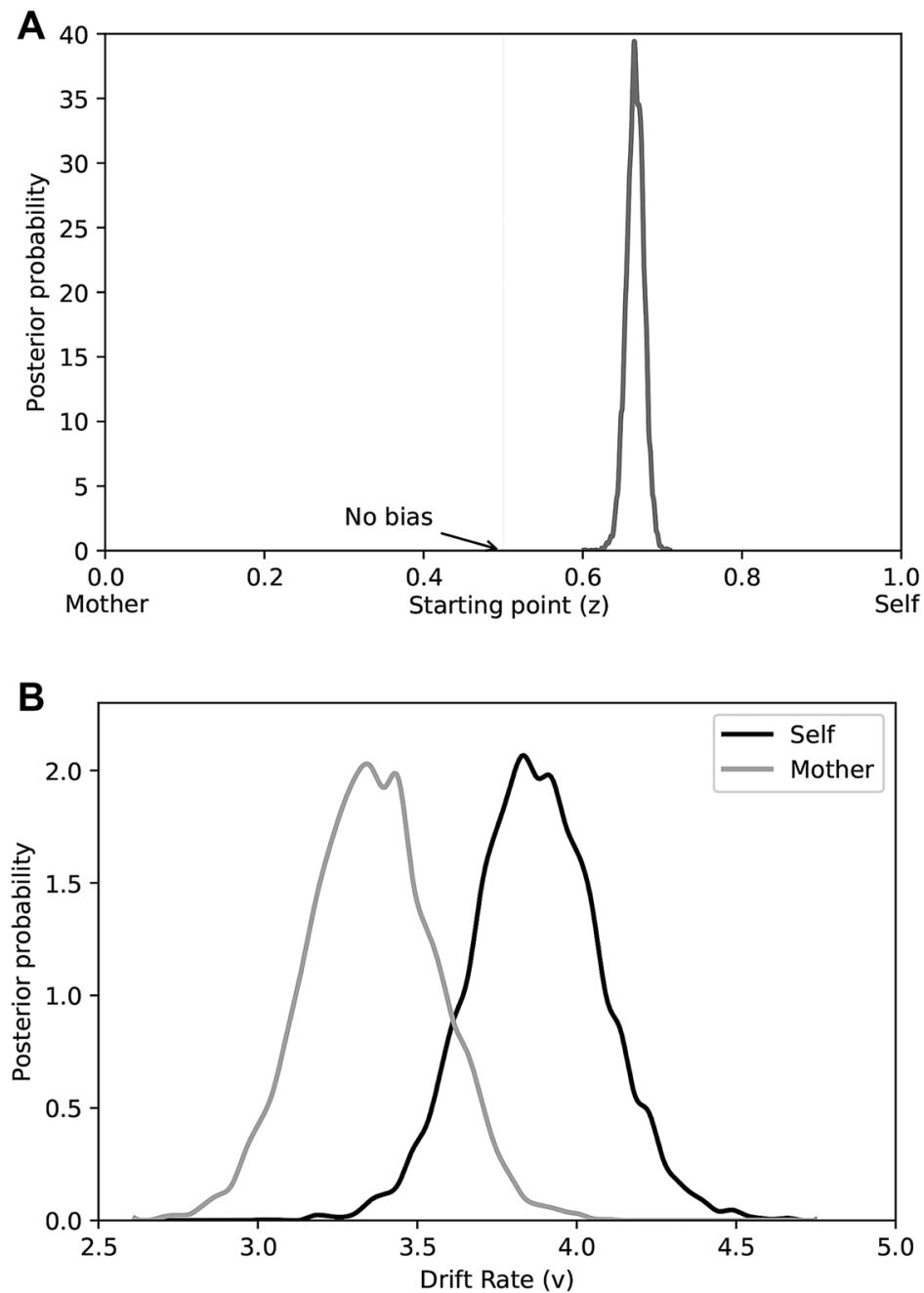

Fig. 3 Mean posterior distributions of starting point $(z)(\mathbf{A})$ and drift rate $(v)$ as a function of Ownership (B). Drift rates for mother have been multiplied by -1

rates were first multiplied by -1 ), indicating that processing efficiency was greater for self-owned than mother-owned objects (respective Ms: 3.87 vs. 3.36, $p_{\text {Bayes }}[$ self $>$ mother $\left.]=.031\right)^{6}$

\footnotetext{
${ }^{6}$ As in Experiment 1, no substantial evidence for cultural effects was observed in the ANOVA, hence adding culture to the HDDM models may not be warranted as it is unlikely to moderate any parameters. To ensure completeness however, models were rerun with culture included. As would be expected based on the ANOVA, culture did not modify any parameters and resulted in larger DIC estimates.
} 


\section{Discussion}

The results of Experiment 2 provided further evidence that ownership influences the speed of object categorization (Golubickis et al. 2018). Compared with pencils or pens that were owned-by-mother, identical self-owned items elicited faster categorization times in participants from both the UK and Hong Kong. These findings replicate Experiment 1 and confirm that self-relevance facilitates perceptual decision-making regardless of putative differences in cultural socialization (see also Sui et al. 2012, 2014). In exploring the processes underpinning task performance, the HDDM analysis revealed that ownership mapped onto the starting value $(z)$ of the DDM, indicating that participants required less evidence when responding to self-owned than friend-owned items. This pre-decisional bias replicates the effect observed in Experiment 1. Additionally, evidence for a difference in the quality of evidence gathering (i.e., drift rate, $v$ ) was also observed, showing that self-owned (vs. mother-owned) objects were processed most efficiently. Corroborating Experiment 1 , these results provide no evidence for a reversal of the self-prioritization effect among Asian participants during a perceptual decision-making task (cf. Sparks et al. 2016). Both Westerners and Asians identified self-owned items more rapidly (and accurately) than mother-owned items (Sui et al. 2012, 2014).

\section{General discussion}

A substantial literature has revealed the effects of self-referential processing on memorial outcomes. In particular, items paired with the self are easier to remember than comparable stimuli associated with other people (e.g., Conway 2005; Conway and Pleydell-Pearce 2000; Cunningham et al. 2008, 2013; Kelley et al. 2002; Maki and McCaul 1985; Rogers et al. 1977; Sparks et al. 2016; Symons and Johnson 1997; Turk et al. 2011). Developing this line of inquiry, Sparks et al. (2016) recently demonstrated important cultural variation in the emergence of this self-memory effect in an ownership task (Cunningham et al. 2008). Whereas Westerners displayed a standard self-memory advantage when mother was the target of comparison (i.e., self $>$ mother), this effect was reversed (i.e., self $<$ mother) among Asian participants.

Based on related research exploring the effects of self-relevance on perceptual decision-making (i.e., self-prioritization, Humphreys and Sui 2016; Sui and Humphreys 2015), here we considered the extent to which differences in cultural socialization impact the effects of ownership on object categorization (Golubickis et al. 2018). Across two experiments, a generally consistent pattern of results was observed. First, ownership triggered a basic self-prioritization effect (i.e., self $<$ mother), with no convincing evidence that this effect differed between Western and Asian participants (Sui et al. 2012, 2014). Second, drift diffusion modeling revealed that this effect was primarily underpinned by a prior (i.e., pre-decisional) bias (Voss et al. 2004, 2013; Wieki et al. 2013; White and Poldrack 2014). Specifically, regardless of their cultural milieu, participants required less evidence when responding to self-owned than mother-owned items (i.e., starting point, $z$ ). In 
Experiment 2, unexpectedly, evidence was also gathered more efficiently for the former than latter stimuli (i.e., drift rate, $v$ ) during decisional processing.

\section{Ownership and object identification}

So why is the memorial advantage for self-relevant material reversed across cultures (Sparks et al. 2016), but the analogous stimulus-prioritization effect in object categorization seemingly resistant to cultural influence (Sui et al. 2012, 2014)? Echoing Sparks et al. (2016), we speculate that the answer may reside in basic differences in the processing requirements of the specific tasks under investigation. Memorial benefits associated with self-referencing are acknowledged to derive from elaborative (i.e., postperceptual) processing operations that enhance stimulus encoding and representation (Conway and Dewhurst 1995; Johnson et al. 1993; Keenan and Baillet 1980; Klein and Loftus 1988; Rogers et al. 1977; Symons and Johnson 1997). As cultural differences in the representation of person knowledge (i.e., degree of self-other overlap in memory, see $\mathrm{Ng}$ and Lai 2009; Wuyun et al. 2014) impact these memory-based operations, divergent effects between Western and Asian participants may naturally emerge (Sparks et al. 2016). In contrast, perceptual tasks of the sort used here (see also Golubickis et al. 2018; Sui et al. 2014) require only the low-level differentiation (i.e., identification) of selfowned from other-owned stimuli. At this basic level of analysis (i.e., self-other discrimination), self-centric responses may be the default product of perceptual processing (Northoff 2016), hence insensitive to cultural variation in patterns of selfconstrual (Sui and Humphreys 2015; Sui and Gu 2017). ${ }^{7}$ Of course, to establish if this is indeed the case additional research will be required. In particular, using an identical set of objects, studies should examine the effects of ownership on both perceptual and memorial measures among Western and Asian participants.

Although egocentrism is most strongly equated with behaviour in early childhood (see Perner 1991; Wimmer and Perner 1983), adults continue to think and respond in a self-centric manner. Indeed, research suggests that all that separates adults from children are corrective processes that counteract and override initial egocentric responses. Thus, it is not that adults are less self-centered than children, it is simply that whereas they have the capacity to adjust their preliminary egocentric reactions, children do not (see Epley and Gilovich 2004; Epley et al. 2004). During early childhood, ownership and egocentrism are tightly intertwined. At around 2 years of age, children begin using possessive pronouns (e.g., mine) and, by the age of 4 , have an established sense of ownership (Hay 2006). Reflecting this understanding, disputes over possession account for a significant proportion of sibling and peer conflicts (Furby 1980; Ramsey 1987; Ross 1996). Intriguingly, variants of these self-biases have also been observed in other primates; notably chimpanzees, orangutans, and capuchin monkeys (e.g., Brosnan et al. 2007; Chen et al. 2006; Lakshminarayanan et al. 2008). Given the primacy of self-other differentiation during early perceptual processing (Northoff 2016; Reddy 2008; Ruffman 2004;

\footnotetext{
${ }^{7}$ It is possible that cultural differences failed to emerge because of the Westernization of our Asian samples (but see Sui et al. 2014). However, it is worth noting that Sparks et al. (2016) reported cultural differences in memory performance using Asian participants in Australia, some of whom had lived there for over 10 years.
} 
Truong and Todd 2017), it is perhaps unsurprising that cultural differences in selfconstrual do not influence the effects of ownership on object categorization (Humphreys and Sui 2016; Sui and Humphreys 2015; Truong and Todd, 2017). As previously noted, however, future research should investigate this issue in greater detail to establish exactly when cultural factors do, and do not, impact object processing and response generation.

\section{Ownership and decisional processing}

Using an HDDM analysis (Wieki et al. 2013), a goal of the current research was to identify the processes that underpin the self-ownership effect. In both Experiments 1 and 2, a largely consistent pattern of effects was observed. First, replicating Golubickis et al. (2018), the self-ownership effect corresponded to a shift in the starting point of evidence accumulation (i.e., z), such that participants required less evidence when responding to self-owned than mother-owned objects (Expts. 1 and 2). This confirms that ownership modulated information-sampling requirements prior to evidence gathering (White and Poldrack 2014). Second, and expectedly, ownership also influenced the rate at which evidence was extracted from stimuli (i.e., v) during decisional processing. Notably, in Experiment 2, self-owned items were processed more efficiently than mother-owned items.

The emergence of pre-decisional biases during decision-making has been traced to the influence of a couple of factors: stimulus probability/expectation and reward (White and Poldrack 2014). For example, when manipulations of response expectancy provide information that one outcome is more likely than another, a higher starting value $(z)$ is adopted for the frequent (vs. infrequent) response (e.g., Domenech and Dreher 2010; Mulder et al. 2012). Similarly, shifting stimulus reward also impacts starting values, such that participants are biased toward rewarding (vs. unrewarding) items (Ashby 1983; Bogacz et al. 2006; Diederich and Busemeyer 2006; Simen et al. 2009; van Ravenzwaaij et al. 2012; White et al. 2010).

Interestingly, whilst self-relevant stimuli are inherently rewarding (Northoff and Hayes 2011), this positivity also extends to self-relevant responses. In a gambling task in which prizes could be gained or lost for either the self or another person, Krigolson et al. (2013) showed that the medial prefrontal reward system was activated when bets were accompanied by a self-relevant response, regardless of the outcome (i.e., win or lose) of each gamble. In other words, simply responding in a self-relevant manner was gratifying. It is possible, therefore, that participants in the current investigation were predisposed toward the response option that was most pleasing/positive (Ma and Han 2010; Stolte et al. 2017), hence the higher starting value for responses to self-owned than mother-owned items. That is, reflecting a reward-driven egocentric strategy (Epley et al. 2004), participants initially assumed all the objects belonged to them, only later adjusting this belief (hence the slowed response times to mother-owned items). A useful task for future research will be to evaluate this possibility.

Intriguingly, contrary to prior research (Golubickis et al. 2018), differences in the efficiency of information gathering during decisional processing were also observed (Expt. 2), such that drift rates ( $v$ ) were higher for self-owned than mother-owned items. Quite what to make of this finding is unclear. Reflecting the rate of evidence 
accumulation during decisional processing, drift rate is highly sensitive to task difficulty and low-level stimulus properties (e.g., Ratcliff and McKoon 2008; Voss et al. 2004). Given however the only difference between the current experiments was the location in which Asian participants were recruited, it seems unlikely that either of these factors contributed to the emergence of the observed difference in drift rates between self-owned and mother-owned items. Additional experimentation is needed to establish the reliability of this effect. This unexpected finding aside, the current work nevertheless underscores the value of drift diffusion modeling when exploring self-prioritization effects in perceptual decision-making (Humphreys and Sui 2016; Sui and Humphreys 2015; Truong and Todd 2017). To fully realize the potential of this approach, future research should consider the effects of ownership on a wider range of objects (e.g., desirable vs. undesirable items, valuable vs. worthless items) among culturally diverse samples to pinpoint exactly when and how self-relevance triggers stimulus prioritization during decisional processing.

\section{Conclusion}

In sum, here were demonstrated the emergence of a self-ownership advantage in both Western and Asian participants during an object-categorization task (Golubickis et al. 2018; Sui et al. 2012, 2014), an effect that was primarily underpinned by a pre-decisional. Contrasted with memory research in which self-biases are often attenuated or even reversed as a function of cultural socialization (Sparks et al. 2016), differences in patterns of self-construal appear to exert little impact on people's ability to discriminate self-owned (or associated) from other-owned (or associated) objects (Sui et al. 2014). The extent of this cross-cultural egocentrism awaits further investigation and analysis.

Open Access This article is distributed under the terms of the Creative Commons Attribution 4.0 International License (http://creativecommons.org/licenses/by/4.0/), which permits unrestricted use, distribution, and reproduction in any medium, provided you give appropriate credit to the original author(s) and the source, provide a link to the Creative Commons license, and indicate if changes were made.

\section{Appendix A}

Bayesian mixed model ANOVA on reaction times

\begin{tabular}{lccccc}
\hline Model comparison & & & & & \\
\hline Models & $\mathrm{P}(\mathrm{M})$ & $\mathrm{P}(\mathrm{Mldata})$ & $\mathrm{BF}_{\mathrm{M}}$ & $\mathrm{BF}_{10}$ & Error $(\%)$ \\
\hline Null model (incl. subject) & 0.200 & 0.022 & 0.089 & 1.000 & \\
Ownership & 0.200 & 0.290 & 1.637 & 13.412 & 0.716 \\
Culture & 0.200 & 0.035 & 0.147 & 1.637 & 2.761 \\
Ownership + culture & 0.200 & 0.464 & 3.466 & 21.439 & 4.745 \\
Ownership + culture + ownership $\times$ culture & 0.200 & 0.188 & 0.928 & 8.693 & 3.065 \\
\hline
\end{tabular}

All models include subject 


\begin{tabular}{lllc}
\hline Analysis of effects & & & \\
\hline Effects & $\mathrm{P}($ incl $)$ & $\mathrm{P}($ inclldata $)$ & $\mathrm{BF}_{\text {Inclusion }}$ \\
\hline Ownership & 0.600 & 0.943 & 11.009 \\
Culture & 0.600 & 0.688 & 1.470 \\
Ownership $\times$ culture & 0.200 & 0.188 & 0.928 \\
\hline
\end{tabular}

\section{Bayesian Mixed Model ANOVA on Accuracy}

\begin{tabular}{llllll}
\hline Model comparison & & & & & \\
\hline Models & $\mathrm{P}(\mathrm{M})$ & $\mathrm{P}(\mathrm{Mldata})$ & $\mathrm{BF}_{\mathrm{M}}$ & $\mathrm{BF}_{10}$ & Error (\%) \\
\hline Null model (incl. subject) & 0.200 & 0.237 & 1.245 & 1.000 & \\
Ownership & 0.200 & 0.488 & 3.806 & 2.054 & 0.814 \\
Culture & 0.200 & 0.072 & 0.310 & 0.303 & 1.466 \\
Ownership + culture & 0.200 & 0.158 & 0.750 & 0.665 & 3.592 \\
Ownership + culture + ownership $\times$ culture & 0.200 & 0.045 & 0.190 & 0.191 & 2.041
\end{tabular}

All models include subject

Analysis of effects

\begin{tabular}{llll}
\hline Effects & $\mathrm{P}($ incl $)$ & $\mathrm{P}($ inclldata $)$ & $\mathrm{BF}_{\text {Inclusion }}$ \\
\hline Ownership & 0.600 & 0.691 & 1.489 \\
Culture & 0.600 & 0.275 & 0.253 \\
Ownership $\times$ culture & 0.200 & 0.045 & 0.190 \\
\hline
\end{tabular}

\section{Appendix B}

\section{Bayesian Mixed Model ANOVA on Reaction Times}

\begin{tabular}{|c|c|c|c|c|c|}
\hline \multicolumn{6}{|l|}{ Model comparison } \\
\hline Models & $\mathrm{P}(\mathrm{M})$ & P(Mldata) & $\mathrm{BF}_{\mathrm{M}}$ & $\mathrm{BF}_{10}$ & Error $(\%)$ \\
\hline Null model (incl. subject) & 0.200 & 0.010 & 0.040 & 1.000 & \\
\hline Ownership & 0.200 & 0.538 & 4.653 & 53.892 & 1.216 \\
\hline Culture & 0.200 & 0.006 & 0.023 & 0.576 & 2.308 \\
\hline Ownership + culture & 0.200 & 0.325 & 1.922 & 32.524 & 2.754 \\
\hline Ownership + culture + ownership $\times$ culture & 0.200 & 0.122 & 0.556 & 12.226 & 3.317 \\
\hline
\end{tabular}

All models include subject 


\begin{tabular}{llll}
\hline Analysis of effects & & & \\
\hline Effects & $\mathrm{P}($ incl $)$ & $\mathrm{P}($ inclldata $)$ & BF $_{\text {Inclusion }}$ \\
\hline Ownership & 0.600 & 0.984 & 41.726 \\
Culture & 0.600 & 0.452 & 0.550 \\
Ownership $\times$ culture & 0.200 & 0.122 & 0.556 \\
\hline
\end{tabular}

\section{Bayesian Mixed Model ANOVA on Accuracy}

\begin{tabular}{lccccc}
\hline Model comparison & & & & & \\
\hline Models & $\mathrm{P}(\mathrm{M})$ & $\mathrm{P}(\mathrm{Mldata})$ & $\mathrm{BF}_{\mathrm{M}}$ & $\mathrm{BF}_{10}$ & Error $(\%)$ \\
\hline Null model (incl. subject) & 0.200 & 0.051 & 0.216 & 1.000 & \\
Ownership & 0.200 & 0.580 & 5.523 & 11.300 & 0.802 \\
Culture & 0.200 & 0.013 & 0.052 & 0.248 & 0.821 \\
Ownership + culture & 0.200 & 0.143 & 0.669 & 2.792 & 1.250 \\
Ownership + culture + ownership $\times$ culture & 0.200 & 0.213 & 1.081 & 4.145 & 2.411 \\
\hline
\end{tabular}

All models include subject

\begin{tabular}{llll}
\hline Analysis of effects & & & \\
\hline Effects & $\mathrm{P}($ incl $)$ & $\mathrm{P}($ inclldata $)$ & $\mathrm{BF}_{\text {Inclusion }}$ \\
\hline Ownership & 0.600 & 0.936 & 9.739 \\
Culture & 0.600 & 0.369 & 0.389 \\
Ownership $\times$ culture & 0.200 & 0.213 & 1.081 \\
\hline
\end{tabular}

\section{References}

Ashby, F. G. (1983). A biased random walk model for two choice reaction times. Journal of Mathematical Psychology, 27, 277-297.

Baars, B. J. (1988). A cognitive theory of consciousness. New York: Cambridge University Press.

Baumeister, R. F. (1998). The self. In D. T. Gilbert, S. T. Fiske, \& G. Lindzey (Eds.), Handbook of social psychology (4th ed., pp. 680-740). New York: McGraw-Hill.

Beggan, J. K. (1992). On the social nature of nonsocial perception: The mere ownership effect. Journal of Personality and Social Psychology, 62, 229-237.

Belk, R. W. (1988). Possessions and the extended self. Journal of Consumer Research, 15, 139-168.

Bogacz, R., Brown, E., Moehlis, J., Holmes, P., \& Cohen, J. D. (2006). The physics of optimal decision making: A formal analysis of models of performance in two-alternative forced-choice tasks. Psychological Review, 113, 700-765.

Boyer, P., Robbins, P., \& Jack, A. I. (2005). Varieties of self-systems worth having. Consciousness and Cognition, 14, 647-660. 
Brosnan, S. F., Jones, O. D., Lambeth, S. P., Mareno, M. C., Richardson, A. S., \& Schapiro, S. J. (2007). Endowment effects in chimpanzees. Current Biology, 17, 1704-1707.

Chen, M. K., Lakshminarayanan, V., \& Santos, L. R. (2006). How basic are behavioral biases? Evidence from capuchin monkey trading behavior. Journal of Political Economy, 114, 517-537.

Chen, P. H. A., Wagner, D. D., Kelley, W. M., Powers, K. E., \& Heatherton, T. F. (2013). Medial prefrontal cortex differentiates self from mother in Chinese: Evidence from self-motivated immigrants. Culture and Brain, 1, 3-15.

Chua, H. F., Boland, J. E., \& Nisbett, R. E. (2005). Cultural variation in eye movements during scene perception. Proceedings of the National Academy of Sciences, 102, 12629-12633.

Cloutier, J., \& Macrae, C. N. (2008). The feeling of choosing: Self-involvement and the cognitive status of things past. Consciousness and Cognition, 17, 125-135.

Conway, M. A. (2005). Memory and the self. Journal of Memory and Language, 53, 594-628.

Conway, M. A., \& Dewhurst, S. A. (1995). The self and recollective experience. Applied Cognitive Psychology, 9, 1-19.

Conway, M. A., \& Pleydell-Pearce, C. W. (2000). The construction of autobiographical memories in the self-memory system. Psychological Review, 107, 261-288.

Cunningham, S. J., Turk, D. J., Macdonald, L. M., \& Macrae, C. N. (2008). Yours or mine? Ownership and memory. Consciousness and Cognition, 17, 312-318.

Dawkins, S., Tian, A. W., Newman, A., \& Martin, A. (2017). Psychological ownership: A review and research agenda. Journal of Organizational Behavior, 38, 163-183.

Diederich, A., \& Busemeyer, J. R. (2006). Modeling the effects of payoff on response bias in a perceptual discrimination task: Bound-change, drift-rate-change, or two-stage-processing hypothesis. Perception \& Psychophysics, 68, 194-207.

Domenech, P., \& Dreher, J. C. (2010). Decision threshold modulation in the human brain. Journal of Neuroscience, 30, 14305-14317.

Dunovan, K. E., Tremel, J. J., \& Wheeler, M. E. (2014). Prior probability and feature predictability interactively bias perceptual decisions. Neuropsychologia, 61, 210-221.

Epley, N., \& Gilovich, T. (2004). Are adjustments insufficient? Personality and Social Psychology Bulletin, 30, 447-460.

Epley, N., Morewedge, C., \& Keysar, B. (2004). Perspective taking in children and adults: Equivalent egocentrism but different correction. Journal of Experimental Social Psychology, 40, 760-768.

Fasig, L. G. (2000). Toddlers' understanding of ownership: Implications for self-concept development. Social Development, 9, 370-382.

Feng, T., Zhao, W., \& Donnay, G. F. (2013). The endowment effect can extend from self to mother: Evidence from an fMRI study. Behavioural Brain Research, 248, 74-79.

Furby, L. (1980). The origins and early development of possessive behavior. Political Psychology, 2, $30-42$.

Gallagher, S. (2000). Philosophical conceptions of the self: Implications for cognitive science. Trends in Cognitive Sciences, 4, 14-21.

Golubickis, M., Falbén, J. K., Sahraie, A., Visokomogilski, A., Cunningham, W. A., Sui, J., et al. (2017). Self-prioritization and perceptual matching: The effects of temporal construal. Memory \& Cognition, 45, 1223-1239.

Golubickis, M., Falbén, J. K., Cunningham, W. A., \& Macrae, C. N. (2018). Exploring the self-ownership effect: Separating stimulus and response biases. Journal of Experimental Psychology. Learning, Memory, and Cognition, 44, 295-306.

Gutchess, A. H., Welsh, R. C., Boduroĝlu, A., \& Park, D. C. (2006). Cultural differences in neural function associated with object processing. Cognitive, Affective, \& Behavioral Neuroscience, 6 , $102-109$.

Han, S., \& Humphreys, G. (2016). Self-construal: A cultural framework for brain function. Current Opinion in Psychology, 8, 10-14.

Han, S., \& Northoff, G. (2008). Culture-sensitive neural substrates of human cognition: A transcultural neuroimaging approach. Nature Reviews Neuroscience, 9, 646-654.

Hay, D. F. (2006). Yours and mine: Toddlers' talk about possessions with familiar peers. British Journal of Developmental Psychology, 24, 39-52.

Heatherton, T. F. (2011). Neuroscience of self and self-regulation. Annual Review of Psychology, 62, 363-390.

Heatherton, T. F., Macrae, C. N., \& Kelley, W. M. (2004). A social brain sciences approach to studying the self. Current Directions in Psychological Science, 13, 190-193. 
Heatherton, T. F., Wyland, C. L., Macrae, C. N., Demos, K. E., Denny, B. T., \& Kelley, W. M. (2006). Medial prefrontal activity differentiates self from close others. Social Cognitive and Affective Neuroscience, 1, 18-25.

Humphreys, G. W., \& Sui, J. (2016). Attentional control and the self: The self-attention network (SAN). Cognitive Neuroscience, 7, 5-17.

James, W. (1890). The principles of psychology. New York: Henry-Holt \& Co.

JASP Team. (2017). JASP (Version 0.8.3.1) [Computer software].

Johnson, M. K., Hashtroudi, S., \& Lindsay, D. S. (1993). Source monitoring. Psychological Bulletin, 114, 3-28.

Kahneman, D., Knetsch, J. L., \& Thaler, R. H. (1991). Anomalies: The endowment effect, loss aversion, and status quo bias. The Journal of Economic Perspectives, 5, 193-206.

Kass, R. E., \& Raftery, A. E. (1995). Bayes factors. Journal of the American Statistical Association, 90, 773-795.

Keenan, J. M., \& Baillet, S. D. (1980). Memory for personally and socially significant events. Attention and Performance, 8, 651-669.

Kelley, W. M., Macrae, C. N., Wyland, C. L., Caglar, S., Inati, S., \& Heatherton, T. F. (2002). Finding the self? An event-related fMRI study. Journal of Cognitive Neuroscience, 14, 785-794.

Kihlstrom, J. F., \& Klein, S. B. (1994). The self as a knowledge structure. In R. S. Wyer \& T. K. Srull (Eds.), Handbook of social cognition (2nd ed., Vol. 2, pp. 153-208). Mahwah, NJ: Erlbaum.

Kim, K., \& Johnson, M. K. (2012). Extended self: Medial prefrontal activity during transient association of self and objects. Social Cognitive and Affective Neuroscience, 7, 199-207.

Kim, K., \& Johnson, M. K. (2015). Distinct neural networks support the mere ownership effect under different motivational contexts. Social Neuroscience, 10, 376-390.

Kitayama, S., \& Uskul, A. K. (2011). Culture, mind, and the brain: Current evidence and future directions. Annual Review of Psychology, 62, 419-449.

Klein, S. B., \& Loftus, J. (1988). The nature of self-referent encoding: The contributions of elaborative and organizational processes. Journal of Personality and Social Psychology, 55, 5-11.

Krigolson, O. E., Hassall, C. D., Balcom, L., \& Turk, D. (2013). Perceived ownership impacts reward evaluation within medial-frontal cortex. Cognitive, Affective, \& Behavioral Neuroscience, 13, 262-269.

Lakshminarayanan, V. R., Chen, M. K., \& Santos, L. R. (2008). Endowment effect in capuchin monkeys. Philosophical Transactions of the Royal Society B, 363, 3837-3844.

Ma, Y., \& Han, S. (2010). Why we respond faster to the self than to others? An implicit positive association theory of self-advantage during implicit face processing. Journal of Experimental Psychology: Human Perception and Performance, 36, 619-633.

Macrae, C. N., Moran, J. M., Heatherton, T. F., Banfield, J. F., \& Kelley, W. M. (2004). Medial prefrontal activity predicts memory for self. Cerebral Cortex, 14, 647-654.

Macrae, C. N., Visokomogilski, A., Golubickis, M., Cunningham, W. A., \& Sahraie, A. (2017). Selfrelevance prioritizes access to visual awareness. Journal of Experimental Psychology: Human Perception and Performance, 43, 438-443.

Maki, R. H., \& McCaul, K. D. (1985). The effects of self-reference versus other-reference on the recall of traits and nouns. Bulletin of the Psychonomic Society, 23, 169-172.

Markus, H. R., \& Kitayama, S. (1991). Culture and the self: Implications for cognition, emotion, and motivation. Psychological Review, 98, 224-253.

Masuda, T., \& Nisbett, R. E. (2001). Attending holistically versus analytically: Comparing context sensitivity of Japanese and Americans. Journal of Personality and Social Psychology, 81, 922-934.

Masuda, T., \& Nisbett, R. E. (2006). Culture and change blindness. Cognitive Science, 30, 381-399.

Mezulis, A. H., Abramson, L. Y., Hyde, J. S., \& Hankin, B. L. (2004). Is there a universal positivity bias in attributions? A meta-analytic review of individual, developmental, and cultural differences in the self-serving attributional bias. Psychological Bulletin, 130, 711-747.

Morewedge, C. K., \& Giblin, C. E. (2015). Explanations of the endowment effect: An integrative review. Trends in Cognitive Sciences, 19, 339-348.

Mulder, M. J., Wagenmakers, E. J., Ratcliff, R., Boekel, W., \& Forstmann, B. U. (2012). Bias in the brain: A diffusion model analysis of prior probability and potential payoff. Journal of Neuroscience, 32, 2335-2343.

Neisser, U. (1988). Five kinds of self-knowledge. Philosophical Psychology, 1, 5-59.

Ng, S. H., \& Lai, J. C. L. (2009). Effects of culture priming on the social connectedness of the bicultural self: A self-reference effect approach. Journal of Cross Cultural Psychology, 40, 170-186. 
Nisbett, R. E., \& Masuda, T. (2003). Culture and point of view. Proceedings of the National Academy of Sciences, 100, 11163-11170.

Northoff, G. (2016). Is the self a higher-order or fundamental function of the brain? The "basis model of self-specificity" and its encoding by the brain's spontaneous activity. Cognitive Neuroscience, 7 , 203-222.

Northoff, G., \& Hayes, D. J. (2011). Is our self nothing but reward? Biological Psychiatry, 69, 1019-1025.

Park, D. C., \& Huang, C.-M. (2010). Culture wires the brain: A cognitive neuroscience perspective. Perspectives on Psychological Science, 5, 391-400.

Perner, J. (1991). Understanding the representational mind. Cambridge, MA: Bradford Books/MIT Press.

Ramsey, P. G. (1987). Possession episodes in young children's social interactions. Journal of Genetic Psychology, 148, 315-324.

Ratcliff, R. (1978). A theory of memory retrieval. Psychological Review, 85, 59-108.

Ratcliff, R., \& McKoon, G. (2008). The diffusion decision model: Theory and data for two-choice decision tasks. Neural Computation, 20, 873-922.

Ratcliff, R., \& Rouder, J. N. (1998). Modeling response times for two-choice decisions. Psychological Science, 9, 347-356.

Ratcliff, R., \& Tuerlinckx, F. (2002). Estimating parameters of the diffusion model: Approaches to dealing with contaminant reaction times and parameter variability. Psychonomic Bulletin \& Review, 9, 438-481.

Ratcliff, R., Smith, P. L., Brown, S. D., \& McKoon, G. (2016). Diffusion decision model: Current issues and history. Trends in Cognitive Sciences, 20, 260-281.

Reddy, V. (2008). How infants know minds. Cambridge, MA: Harvard University Press.

Rogers, T. B., Kuiper, N. A., \& Kirker, W. S. (1977). Self-reference and the encoding of personal information. Journal of Personality and Social Psychology, 35, 677-688.

Ross, H. S. (1996). Negotiating principles of entitlement in sibling property disputes. Developmental Psychology, 32, 90-101.

Rouder, J. N., Morey, R. D., Speckman, P. L., \& Province, J. M. (2012). Default Bayes factors for ANOVA designs. Journal of Mathematical Psychology, 56, 356-374.

Ruffman, T. (2004). Children's understanding of mind: Constructivist but theory-like. Behavioral and Brain Sciences, 27, 120-121.

Schmitz, T. W., \& Johnson, S. C. (2007). Relevance to self: A brief review and framework of neural systems underlying appraisal. Neuroscience and Biobehavioral Reviews, 31, 585-596.

Schönbrodt, F. D., Wagenmakers, E. J., Zehetleitner, M., \& Perugini, M. (2017). Sequential hypothesis testing with Bayes factors: Efficiently testing mean differences. Psychological Methods, 22, 322-339.

Simen, P., Contreras, D., Buck, C., Hu, P., Holmes, P., \& Cohen, J. D. (2009). Reward rate optimization in two-alternative decision making: Empirical tests of theoretical predictions. Journal of Experimental Psychology: Human Perception and Performance, 35, 1865-1897.

Spaniol, J., Madden, D. J., \& Voss, A. (2006). A diffusion model analysis of adult age differences in episodic and semantic long-term memory retrieval. Journal of Experimental Psychology. Learning, Memory, and Cognition, 32, 101-117.

Sparks, S., Cunningham, S. J., \& Kritikos, A. (2016). Culture modulates implicit ownership-induced selfbias in memory. Cognition, 153, 89-98.

Spiegelhalter, D. J., Best, N. G., Carlin, B. P., \& Van der Linde, A. (1998). Bayesian deviance, the effective number of parameters, and the comparison of arbitrarily complex models. Research Report, 98-009.

Stolte, M., Humphreys, G., Yankouskaya, A., \& Sui, J. (2017). Dissociating biases towards the self and positive emotion. The Quarterly Journal of Experimental Psychology, 70, 1011-1022.

Sui, J., \& Gu, X. (2017). Self as object: Emerging trends in self research. Trends in Neurosciences, 40, 643-653.

Sui, J., \& Humphreys, G. W. (2015). The integrative self: How self-reference integrates perception and memory. Trends in Cognitive Sciences, 19, 719-728.

Sui, J., He, X., \& Humphreys, G. W. (2012). Perceptual effects of social salience: Evidence from selfprioritization effects on perceptual matching. Journal of Experimental Psychology: Human Perception and Performance, 38, 1105-1117. 
Sui, J., Sun, Y., Peng, K., \& Humphreys, G. W. (2014). The automatic and the expected self: Separating self-and familiarity biases effects by manipulating stimulus probability. Attention, Perception, \& Psychophysics, 76, 1176-1184.

Symons, C. S., \& Johnson, B. T. (1997). The self-reference effect in memory: A meta-analysis. Psychological Bulletin, 121, 371-394.

Truong, G., \& Todd, R. M. (2017). SOAP opera: Self as object and agent in prioritizing attention. Journal of Cognitive Neuroscience, 29, 937-952.

Turk, D. J., Van Bussel, K., Waiter, G. D., \& Macrae, C. N. (2011). Mine and me: Exploring the neural basis of object ownership. Journal of Cognitive Neuroscience, 23, 3657-3668.

van Ravenzwaaij, D., Mulder, M. J., Tuerlinckx, F., \& Wagenmakers, E. J. (2012). Do the dynamics of prior information depend on task context? An analysis of optimal performance and an empirical test. Frontiers in Psychology, 3, 132. https://doi.org/10.3389/fpsyg.2012.00132.

Vandekerckhove, J., Tuerlinckx, F., \& Lee, M. D. (2011). Hierarchical diffusion models for two-choice response times. Psychological Methods, 16, 44-62.

Voss, A., Rothermund, K., \& Voss, J. (2004). Interpreting the parameters of the diffusion model. Memory \& Cognition, 32, 1206-1220.

Voss, A., Voss, J., \& Klauer, K. C. (2010). Separating response-execution bias from decision bias: Arguments for an additional parameter in Radcliff's diffusion model. British Journal of Mathematical and Statistical Psychology, 63, 539-555.

Voss, A., Nagler, M., \& Lerche, V. (2013). Diffusion models in experimental psychology. Experimental Psychology, 60, 385-402.

Wagenmakers, E. J. (2009). Methodological and empirical developments for the Ratcliff diffusion model of response times and accuracy. European Journal of Cognitive Psychology, 21, 641-671.

Wagenmakers, E. J., Wetzels, R., Borsboom, D., \& van der Maas, H. L. (2011). Why psychologists must change the way they analyze their data: The case of psi: Comment on Bem (2011). Journal of Personality and Social Psychology, 100, 426-432.

Wang, G., Mao, L., Ma, Y., Yang, X., Cao, J., Liu, X., et al. (2012). Neural representations of close others in collectivist brains. Social Cognitive and Affective Neuroscience, 7, 220-222.

White, C. N., \& Poldrack, R. A. (2014). Decomposing bias in different types of simple decisions. Journal of Experimental Psychology. Learning, Memory, and Cognition, 40, 385-398.

White, C. N., Ratcliff, R., Vasey, M. W., \& McKoon, G. (2010). Using diffusion models to understand clinical disorders. Journal of Mathematical Psychology, 54, 39-52.

Wieki, T. V., Sofer, I., \& Frank, M. J. (2013). HDDM: Hierarchical Bayesian estimation of the driftdiffusion model in python. Frontiers in Neuroinformatics, 7, 14. https://doi.org/10.3389/fninf.2013. 00014.

Wimmer, H., \& Perner, J. (1983). Beliefs about beliefs: Representation and constraining function of wrong beliefs in young children's understanding of deception. Cognition, 13, 103-128.

Wuyun, G., Shu, M., Cao, Z., Huang, W., Zou, X., Li, S., et al. (2014). Neural representations of the self and the mother for Chinese individuals. PLOS ONE. https://doi.org/10.1371/journal.pone.0091556.

Zhao, W., Feng, T., \& Kazinka, R. (2014). The extensibility of the endowment effect to others is mediated by degree of intimacy. Asian Journal of Social Psychology, 17, 296-301.

Zhu, Y., \& Han, S. (2008). Cultural differences in the self: From philosophy to psychology and neuroscience. Social and Personality Compass, 2(5), 1799-1811.

Zhu, Y., \& Zhang, L. (2002). An experimental study on the self-reference effect. Science in China, Series C: Life Sciences, 45, 120-128.

Zhu, Y., Zhang, L., Fan, J., \& Han, S. (2007). Neural basis of cultural influence on self-representation. Neuroimage, 34, 1310-1316.

\section{Affiliations}

Marius Golubickis ${ }^{1}$ (D) Nerissa S. P. Ho ${ }^{2} \cdot$ Johanna K. Falbén $^{1} \cdot$ Kirsten M. Mackenzie ${ }^{1} \cdot$ Angela Boschetti $^{1} \cdot$ William A. Cunningham $^{3}$. C. Neil Macrae ${ }^{1}$ 
$\bowtie$ Marius Golubickis

marius.golubickis.10@aberdeen.ac.uk

1 School of Psychology, King's College, University of Aberdeen, Aberdeen AB24 3FX, Scotland, UK

2 Division of Social Sciences, Community College of City University, Kowloon Tong, Hong Kong

3 Department of Psychology, University of Toronto, Toronto, Canada 